\title{
Remoção de sólidos suspensos e totais em biofiltros operando com esgoto doméstico primário para reuso na agricultura ${ }^{1}$
}

\author{
Rafael Oliveira Batista ${ }^{2}$, Antônio Alves Soares ${ }^{3}$, Delfran Batista dos Santos ${ }^{4}$, Joel Medeiros Bezerra ${ }^{5}$, \\ Adriana de Fátima Mendes Oliveira ${ }^{6}$
}

\begin{abstract}
RESUMO
Este trabalho objetivou analisar a remoção de sólidos suspensos e totais em biofiltros, preenchidos com lixo compostado, bagaço de cana-de-açúcar e serragem de madeira, submetidos às taxas de aplicação do esgoto doméstico de $0,5,1,0$ e 1,5 $\mathrm{m}^{3} \mathrm{~m}^{-2} \mathrm{~d}^{-1}$, em Viçosa-MG. Para isso, foi montada uma bancada experimental, constituída de 27 biofiltros, em área experimental da Universidade Federal de Viçosa. As concentrações de sólidos suspensos e totais foram determinadas, mensalmente, durante período de 153 dias. O experimento foi montado no esquema de parcelas subsubdivididas, tendo, nas parcelas, as taxas de aplicação do esgoto doméstico; nas subparcelas, os tipos de material orgânico e, nas subsubparcelas, os períodos de avaliação, no delineamento em blocos casualizados, com três repetições. Os resultados indicaram que os biofiltros proporcionaram remoções de sólidos suspensos e totais de até 82 e 46\%, no esgoto doméstico, após 153 dias de operação; a serragem de madeira foi o tipo de material orgânico filtrante com melhor desempenho no tratamento de esgoto doméstico; as aplicações de taxas de $0,5,1,0$ e $1,5 \mathrm{~m}^{3} \mathrm{~m}^{-2} \mathrm{~d}^{-1}$ de esgoto não apresentaram diferenças quanto à remoção de sólidos suspensos e totais; e a utilização de biofiltros minimiza a obstrução de emissores causada por sólidos suspensos, quando do aproveitamento agrícola de esgoto doméstico, por via do sistema de irrigação por gotejamento.
\end{abstract}

Palavras-chave: tecnologia limpa, água residuária, poluentes.

\section{ABSTRACT \\ Removal of suspended and total solids in biofilters operating with primary domestic sewage for reuse in agriculture}

This study aimed to evaluate the removal of suspended and total solids in biofilters filled with composted waste, sugar cane bagasse and sawdust submitted to the application rates of domestic sewage of $0.5,1.0$ and $1.5 \mathrm{~m}^{3} \mathrm{~m}^{-2} \mathrm{~d}^{-1}$ in Viçosa-MG. An experimental test unit was set up in experimental area of the Federal University of Viçosa. The concentrations of suspended and total solids were determined monthly during a period of 153 days. The experiment was arranged in a split split plot design, with the application rates of domestic sewage in the plots, the types of organic material in the splitplots and evaluation period in the split-splitplots, in a completely randomized design with three replications. The results indicated that the biofilter provided removal of suspended and total solids up to 82 and $46 \%$

\footnotetext{
Recebido para publicação em 17/01/2012 e aprovado em 07/11/2012.

${ }^{1}$ Financiado pela CAPES. Parte de relatório de pós-doutorado do primeiro autor.

${ }^{2}$ Engenheiro Agrícola, Doutor. Departamento de Ciências Ambientais e Tecnológicas, Universidade Federal Rural do Semi-Árido, Avenida Francisco Mota, 572, Bairro Presidente Costa e Silva, 59625-900, Mossoró, Rio Grande do Norte, Brasil. rafaelbatista@ufersa.edu.br (autor para correspondência).

${ }^{3}$ Engenheiro Agrícola, Doutor. Departamento de Engenharia Agrícola, Universidade Federal de Viçosa, Campus Viçosa, Avenida Peter Henry Rolfs, s/n, 36570-000, Viçosa, Minas Gerais, Brasil. aasoares@ufv.br

${ }^{4}$ Engenheiro-Agrônomo. Instituto Federal de Educação, Ciência e Tecnologia Baiano, Estrada da Igara, s/n, Zona Rural, 48970-000, Senhor do Bonfim, Bahia, Brasil. delfran.batista@gmail.com

${ }^{5}$ Engenheiro Agrícola e Ambiental. Mestrando em Engenharia Agrícola do Departamento de Tecnologia Rural, Universidade Federal Rural de Pernambuco, 52171-900, Recife, Pernambuco, Brasil. joel_medeiros@oi.com.br

${ }^{6}$ Graduanda em Agronomia. Departamento de Ciências Ambientais e Tecnológicas, Universidade Federal Rural do Semi-Árido, Avenida Francisco Mota, 572, Bairro Presidente Costa e Silva, 59625-900, Mossoró, Rio Grande do Norte, Brasil. oliveira.adrianamendes@gmail.com
} 
of the domestic waste after 153 days of operation, the sawdust was the type of filter that gave the best performance for the treatment of domestic waste, the application rates of domestic waste of $0.5,1.0$ and $1.5 \mathrm{~m}^{3} \mathrm{~m}^{-2} \mathrm{~d}^{-1}$ showed no difference regarding the removal of suspended and total solids and the use of biofilters minimizes the clogging caused by suspended solids when using domestic waste in agriculture via drip irrigation system.

Key words: clean technology, wastewater, pollutants.

\section{INTRODUÇÃO}

O modelo atual de urbanização tem resultado na geração de grandes quantidades de esgotos sanitários. Por essa razão, a inadequação dos sistemas de esgotamento sanitário é a principal causa de doenças e de poluição ambiental (Zhao et al., 2010).

Segundo a Pesquisa Nacional de Saneamento Básico, de 2008, 44,8\% dos municípios brasileiros não possuem rede coletora de esgoto doméstico e apenas $28,5 \%$ desses municípios dispõem de sistemas de tratamento de esgoto sanitário (IBGE, 2010).

No que concerne às companhias de saneamento, o lançamento de esgoto doméstico bruto em corpos hídricos altera as características da água, a partir do ponto de lançamento, e compromete sua qualidade para consumo humano, ou, mesmo, para uso em atividades agropecuárias (Von Sperling, 2011).

A utilização de biofiltros com distintos resíduos industriais e agroindustriais (Moon et al., 2010; Xing et al., 2011; Fernández-Gómez et al., 2012), no tratamento de esgoto doméstico primário, favorece a utilização de radiação solar, como tratamento terciário. As camadas filtrantes do biofiltro retêm a maior parte dos sólidos suspensos, reduzindo a turbidez, favorecendo a penetração de radiação ultravioleta (UVA e UVB) dentro do meio líquido. Os comprimentos de onda da radiação solar danificam a membrana citoplasmática do micro-organismo patogênico, resultando, assim, na sua inativação (Sanches-Roman et $a l ., 2007)$. Além disso, no que se refere ao reuso da água, por via do sistema de irrigação por gotejamento, essa tecnologia propicia a redução dos riscos de obstrução física de emissores (Batista et al., 2010).

O tratamento de esgotos domésticos com biofiltros configura-se em uma tecnologia limpa de baixo custo, fácil operação e alta eficiência de remoção de diversos poluentes físico-químicos (Kim \& Sorial, 2007; Jeong et al., 2008; Jun \& Wenfeng, 2009; Fu et al., 2011; Wang et al., 2011).

Batista et al. (2012) trabalharam com biofiltros preenchidos com lixo compostado, bagaço de cana-de-açúcar e serragem de madeira, abastecidos com esgoto doméstico primário, nas taxas de 0,$5 ; 1,0 ; \mathrm{e} 1,5 \mathrm{~m}^{3} \mathrm{~m}^{-2} \mathrm{~d}^{-1}$. Os referidos autores concluíram que, com os biofiltros com serragem de madeira, submetidos às taxas de aplicação de 1,0 e 1,5 $\mathrm{m}^{3} \mathrm{~m}^{-2} \mathrm{~d}^{-1}$, ocorreu diminuição da condutividade elétrica de até 59 e $53 \%$, respectivamente, durante o período de operação. Em outro trabalho, Batista et al. (2011) constataram remoções de 60,80 e $66 \%$ e de 65,71 e $80 \%$, na demanda química de oxigênio (DQO) e na demanda bioquímica de oxigênio (DBO), com os biofiltros preenchidos com lixo compostado, bagaço de cana-de-açúcar e serragem de madeiras, operando nas taxas de 1,0 e 1,5 $\mathrm{m}^{3}$ $\mathrm{m}^{-2} \mathrm{~d}^{-1}$ com esgoto doméstico primário. Laws (2003) analisou a qualidade da filtração de biofiltros, operando com esgoto doméstico bruto, na taxa de $1 \mathrm{~m}^{3} \mathrm{~m}^{-2} \mathrm{~d}^{-1}$. Os resultados indicaram que, no esgoto doméstico tratado, houve remoção de 95, 80 e 70\% nas concentrações de DQO, sólidos suspensos totais e nitrogênio, respectivamente.

Este trabalho objetivou analisar a remoção de sólidos suspensos e totais, em biofiltros preenchidos com serragem de madeira, bagaço de cana-de-açúcar e lixo compostado domiciliar, operando nas taxas de aplicação do esgoto doméstico de 0,$5 ; 1,0 ;$ e $1,5 \mathrm{~m}^{3} \mathrm{~m}^{2} \mathrm{~d}^{-1}$.

\section{MATERIAIS E MÉTODO}

O trabalho foi realizado na Unidade Piloto de Tratamento de Água Residuária e Agricultura Irrigada (UTAR), da Universidade Federal de Viçosa (UFV), situada em Viçosa-MG, tendo como coordenadas geográficas: latitude $20^{\circ} 45^{\prime} 14^{\prime \prime} \mathrm{S}$, longitude $42^{\circ} 52^{\prime} 53^{\prime \prime} \mathrm{W}$ e a altitude média de $650 \mathrm{~m}$.

A UTAR é abastecida com vazão de $2 \mathrm{~L} \mathrm{~s}^{-1}$ de esgoto doméstico bruto, proveniente de 600 pessoas que habitam o condomínio residencial Bosque Acamari, em Viçosa-MG. O efluente aplicado na superfície dos biofiltros passou por um sistema preliminar, constituído de uma caixa de areia, e por um tratamento primário com tanque séptico (tempo de retenção hidráulica de 14 horas).

A bancada experimental foi constituída de 27 módulos em alvenaria, nas dimensões de 1,0 m de largura por 2,0 m de comprimento e 1,2 m de altura. Nestes módulos foram ensaiados três tipos de materiais orgânicos filtrantes: bagaço de cana-de-açúcar, com granulometria de 6 a $10 \mathrm{~mm}$; serragem de madeira, com granulometria de 2,0 a 5,0 mm e 
lixo orgânico domiciliar compostado, com granulometria de 2,0 a 5,0 mm, e três taxas de aplicação de esgoto doméstico bruto: 0,$5 ; 1,0$ e $1,5 \mathrm{~m}^{3} \mathrm{~m}^{-2} \mathrm{dia}^{-1}$. Na Tabela 1 , estão apresentadas as características dos resíduos utilizados no preenchimento dos biofiltros.

Os 27 biofiltros destinados ao tratamento de esgoto doméstico foram preenchidos com quatro camadas de meios filtrantes, sendo duas de materiais orgânicos e duas de materiais inorgânicos, conforme apresentado na Figura 1 . A primeira camada tem $0,20 \mathrm{~m}$ de espessura, sendo constituída de material orgânico, a que foram adicionadas minhocas da espécie Eisenia phoetida, conforme recomendado por Xing et al. (2011). A segunda camada, de $0,40 \mathrm{~m}$ de espessura, foi preenchida somente com material orgânico, enquanto, a terceira e quarta camadas foram compostas por britas $n^{\circ} 0$ e 1 , perfazendo espessura de $0,40 \mathrm{~m}$, visando a favorecer a drenagem no biofiltro e garantir a aeração contínua no sistema. No fundo de cada módulo, foi instalado um sistema de drenagem, composto por tubos de PVC, com diâmetro nominal de $32 \mathrm{~mm}$, para a coleta do efluente tratado (Figura 1).

Na montagem dos biofiltros, os materiais orgânicos foram acondicionados nas bancadas de forma gradual, em camadas de 0,2 m de espessura, sob compressão de 0,167 $\mathrm{kgf} \mathrm{cm}^{-2}\left(16,35 \mathrm{kN} \mathrm{m}^{-2}\right)$, pressão exercida por um homem, de $50 \mathrm{kgf}$ de peso, até ser atingida a altura de $0,60 \mathrm{~m}$.

Os módulos foram circundados por sombrite, para evitar a ação de predadores naturais das minhocas, e abastecidos com esgoto doméstico, provenientes do tanque séptico com tempo de detenção de 14 horas, utilizando-se três motobombas de $3 \mathrm{cv}$, três reservatórios de $2,5 \mathrm{~m}^{3} \mathrm{e}$ tubos de PVC de $25 \mathrm{~mm}$, perfurados ao longo do seu comprimento, formando pequenos tubos janelados.

Para avaliação da qualidade do efluente, foram obtidas amostras compostas a montante e a jusante dos biofiltros, a partir de amostras simples coletadas em quatro horários (às 8, 11, 14 e 17 horas), uma vez a cada 30 dias, durante 153 dias. As análises físicas foram realizadas no Laboratório de Qualidade de Água da UFV. As concentrações dos sólidos suspensos (SS) foram obtidas pelo método gravimétrico, com a utilização de membranas de fibra de vidro $(0,45 \mu \mathrm{m}$ de diâmetro de poro); enquanto as concentrações de sólidos totais foram obtidas pelo método gravimétrico.
O experimento foi montado em esquema de parcelas subsubdivididas, tendo, nas parcelas, as taxas de aplicação do esgoto doméstico $\left(0,5 ; 1,0 ;\right.$ e $\left.1,5 \mathrm{~m}^{3} \mathrm{~m}^{2} \mathrm{~d}^{-1}\right)$; nas subparcelas, os tipos de material orgânico (lixo compostado, bagaço de cana-de-açúcar e serragem de madeira) e, nas subsubparcelas, os tempos das avaliações (agosto, setembro, outubro, novembro e dezembro de 2009), no delineamento inteiramente casualizado, com três repetições.

Os dados foram submetidos à análise de variância e teste de média. Na análise de variância, foi utilizado o teste F, a 1 e $5 \%$ de probabilidade. As médias foram comparadas, utilizando-se o teste de Tukey, a 5\% de probabilidade. Nas análises estatísticas, foi utilizado o programa computacional SAEG 9.1 (Ribeiro Júnior \& Melo, 2008).

\section{RESULTADOS E DISCUSSÃO}

Estão apresentadas, na Figura 2, as concentrações de sólidos suspensos (SS) de amostras de esgoto doméstico coletadas a montante e a jusante dos biofiltros com lixo compostado, bagaço de cana-de-açúcar e serragem de madeira, submetidos às taxas de aplicação do esgoto doméstico de $0,5,1,0$ e $1,5 \mathrm{~m}^{3} \mathrm{~m}^{-2} \mathrm{~d}^{-1}$.

Nota-se que houve remoção gradativa de SS, nos efluentes coletados a jusante dos biofiltros, ao longo do período experimental. Após 153 dias de operação, a concentração média de SS a montante dos biofiltros foi de $144 \mathrm{mg} \mathrm{L}^{-1}$, enquanto, a jusante dos biofiltros preenchidos com lixo compostado, bagaço de cana-de-açúcar e serragem de madeira, na taxa de aplicação de esgoto doméstico de $0,5 \mathrm{~m}^{3} \mathrm{~m}^{-2} \mathrm{~d}^{-1}$, os valores foram de 57,31 e $64 \mathrm{mg}$ $\mathrm{L}^{-1}$, respectivamente, com remoções médias 60, 78 e $56 \%$. Essas taxas de remoção encontram-se dentro da faixa de 56 a $67 \%$, obtida por Zhao et al. (2010), com biofiltros, tratando efluente de lodo de esgoto durante 170 dias. No mesmo momento, para a taxa de aplicação de esgoto doméstico de $1,0 \mathrm{~m}^{3} \mathrm{~m}^{-2} \mathrm{~d}^{-1}$, verifica-se que a concentração média de SS a montante dos biofiltros foi de $196 \mathrm{mg} \mathrm{L}^{-1}$, sendo reduzida para 55, 43 e $27 \mathrm{mg} \mathrm{L}^{-1}$ a jusante dos biofiltros com lixo compostado, bagaço de cana-de-açúcar e serragem de madeira, apresentando remoções médias de 72,78 e $86 \%$, similares às da faixa de 72 a $79 \%$ obtida por Xing et al. (2011), com biofiltros operando nas taxas de aplicação de esgoto doméstico de 2,4, 4,8, 6,0 e

Tabela 1. Características dos resíduos utilizados no preenchimento dos biofiltros usados para tratamento de esgoto doméstico

\begin{tabular}{lccccc}
\hline $\begin{array}{l}\text { Resíduo de preenchimento } \\
\text { dos biofiltros }\end{array}$ & $\begin{array}{c}\text { Umidade } \\
(\boldsymbol{\%})\end{array}$ & $\begin{array}{c}\text { TDH } \\
(\text { Minutos })\end{array}$ & $\begin{array}{c}\text { Porosidade } \\
(\boldsymbol{\%})\end{array}$ & $\mathbf{p H}$ & $\begin{array}{c}\text { Temperatura } \\
\left({ }^{\mathbf{0}} \mathbf{C}\right)\end{array}$ \\
\hline Lixo compostado & 39,3 & 12 & 74 & 3,9 & 27,7 \\
Bagaço de cana-de-açúcar & 31,1 & 8 & 62 & 5,0 & 26,4 \\
Serragem de madeira & 43,7 & 10 & 64 & 8,4 & 27,0 \\
\hline
\end{tabular}

Nota: TDH - tempo de detenção hidráulica. 
$6,7 \mathrm{~m}^{3} \mathrm{~m}^{-2} \mathrm{~h}^{-1}$, durante $31,30,32$ e 30 dias de operação, respectivamente. Na taxa de aplicação de esgoto doméstico de $1,5 \mathrm{~m}^{3} \mathrm{~m}^{-2} \mathrm{~d}^{-1}$, após 153 dias de operação, a concentração de SS a montante dos biofiltros foi de $160 \mathrm{mg} \mathrm{L}^{-1} \mathrm{e}$, a jusante, com lixo compostado, bagaço de cana-de-açúcar e serragem de madeira, os valores de SS foram de 68, 23 e $46 \mathrm{mg} \mathrm{L}^{-1}$, resultando em remoções médias de 58, 86 e $71 \%$, respectivamente. Essas taxas de remoção foram inferiores às da faixa de $56 \mathrm{a} 67 \%$ apresentada por Zhao et al. (2010), em seu estudo com biofiltros, operando com efluente de lodo de esgoto, durante 170 dias (Figura 2).
Constam, na Figura 3, as concentrações de sólidos totais (ST), de amostras de esgoto doméstico coletadas a montante e a jusante dos biofiltros com lixo compostado, bagaço de cana-de-açúcar e serragem de madeira, submetidos às taxas de aplicação de 0,5, 1,0 e 1,5 m $\mathrm{m}^{3} \mathrm{~m}^{-2} \mathrm{~d}^{-1}$.

Observa-se, para os meses de agosto e setembro de 2009, que os valores de ST dos esgotos domésticos, coletados a jusante dos biofiltros com lixo compostado, submetido às taxas de aplicação de $0,5,1,0 \mathrm{e} 1,5 \mathrm{~m}^{3} \mathrm{~m}^{-2} \mathrm{~d}^{-1}$, foram superiores aos valores de ST do esgoto doméstico coletado a montante, por causa do arraste, principalmen-
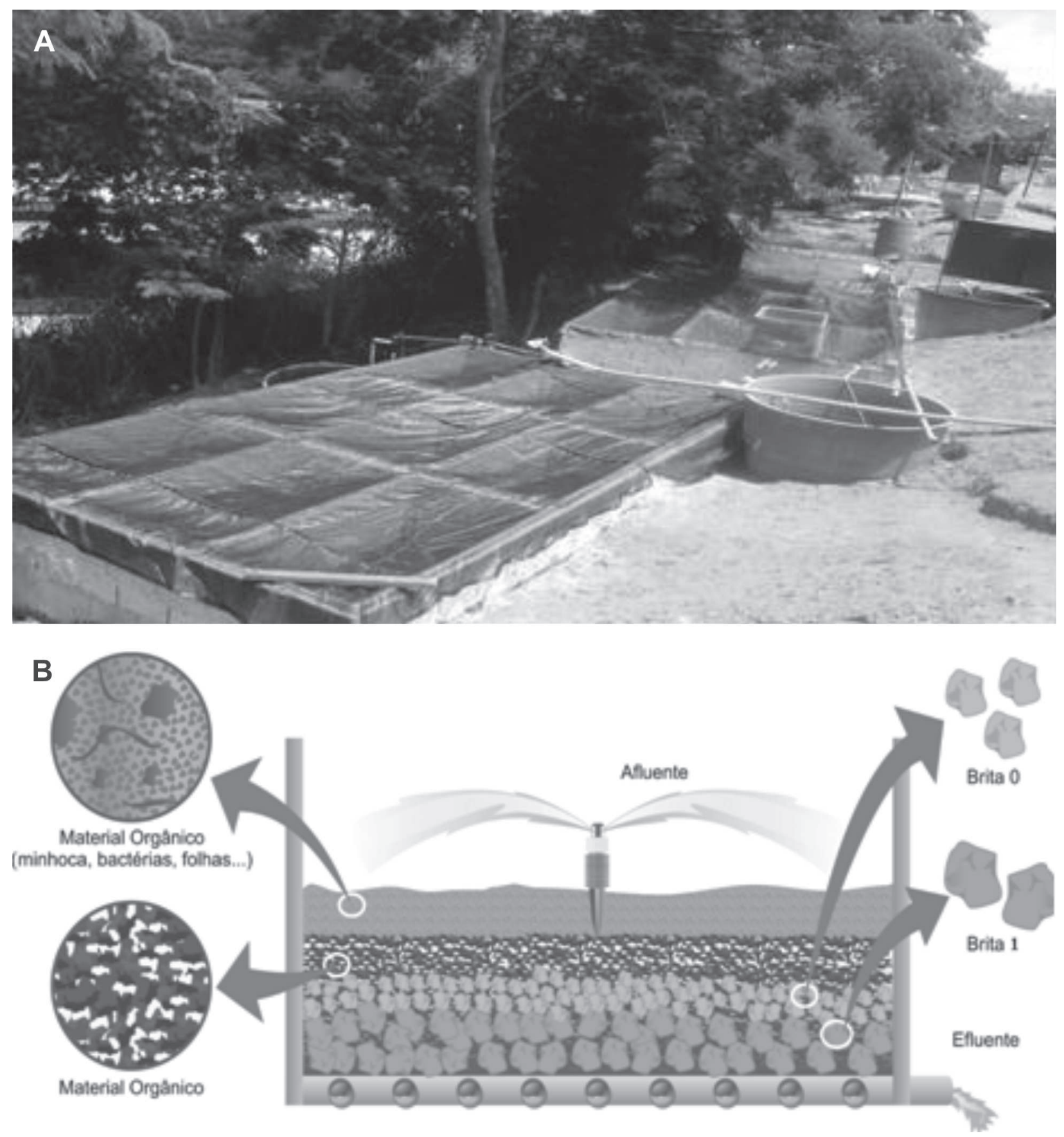

Figura 1. Ilustração da bancada experimental dos biofiltros construídos em alvenaria (a) e detalhe das camadas filtrantes dos biofiltros preenchidos com material orgânico e inorgânico (b). 
te, dos sólidos dissolvidos pelo esgoto doméstico, quando de sua passagem através do meio filtrante, com pouca formação de biofilme. A partir do mês de outubro, houve a formação de biofilme entre as partículas orgânicas dos meios filtrantes. Geralmente, esse biofilme é constituído por substâncias aglutinantes, que permitem a adesão dos sólidos. Sendo assim, com a presença mais acentuada de micro-organismos nos meios filtrantes, o processo de filtração dos sólidos totais tornou-se mais eficiente, em relação ao início do experimento (Wang et al., 2011; Xing et al., 2011).

Verifica-se que houve remoção de ST, pelos biofiltros, a partir de outubro de 2009. Após 153 dias de operação, o esgoto doméstico, coletado a montante dos biofiltros sob taxa de aplicação de $0,5 \mathrm{~m}^{3} \mathrm{~m}^{-2} \mathrm{~d}^{-1}$, apre- sentou concentração de ST de $778 \mathrm{mg} \mathrm{L}^{-1}$; enquanto, nos esgotos domésticos coletados a jusante dos biofiltros preenchidos com lixo compostado, bagaço de canade-açúcar e serragem de madeira, as concentrações de ST foram reduzidas para 606, 478 e $536 \mathrm{mg} \mathrm{L}^{-1}$, com remoções de 22,39 e $31 \%$, respectivamente. Nos biofiltros sob taxa de aplicação de $1,0 \mathrm{~m}^{3} \mathrm{~m}^{-2} \mathrm{~d}^{-1}$, a concentração de ST no esgoto doméstico coletado a montante foi de $792 \mathrm{mg} \mathrm{L}^{-1}$ e, nos esgotos domésticos coletados a jusante dos biofiltros preenchidos com lixo compostado, bagaço de cana-de-açúcar e serragem de madeira, essas concentrações foram de 526, 476 e $458 \mathrm{mg} \mathrm{L}^{-1}$, indicando remoções de ST de 34, 40 e 42\%, respectivamente. Para os biofiltros sob taxa de aplicação de $1,5 \mathrm{~m}^{3} \mathrm{~m}^{-2} \mathrm{~d}^{-1}$, a concentração de ST no esgoto doméstico coletado a
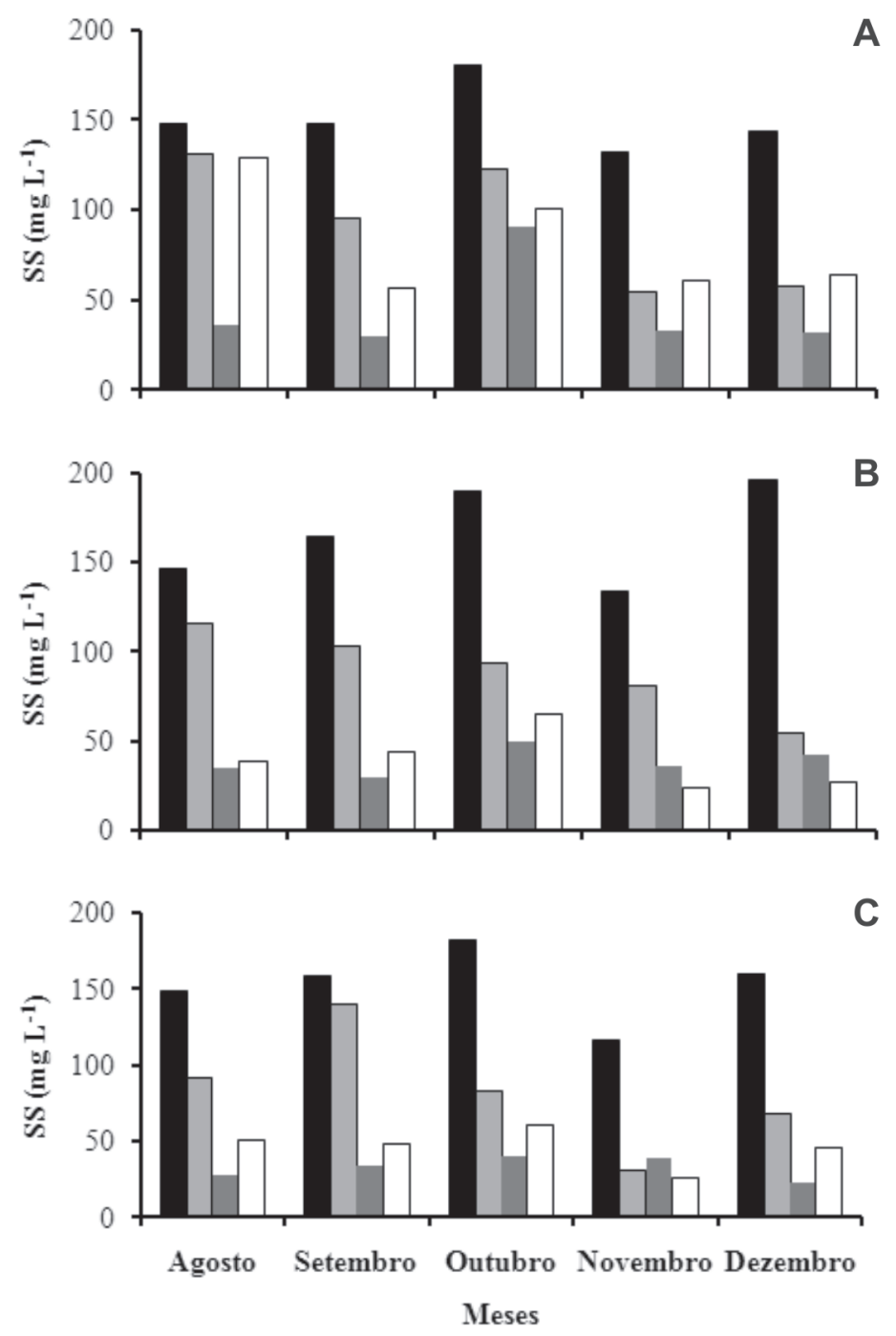

- AFL $\square \mathrm{EBL}$ EBB $\square \mathrm{EBS}$

Figura 2. Concentrações dos sólidos suspensos (SS) das amostras de esgoto doméstico, coletadas a montante e a jusante dos biofiltros, submetidos às taxas de aplicação de 0,5 (a), 1,0 (b) e 1,5 (c) $\mathrm{m}^{3} \mathrm{~m}^{-2} \mathrm{~d}^{-1}$ (AFL - esgoto doméstico sem tratamento, EBL esgoto doméstico coletado a jusante do filtro biológico com lixo compostado, EBB - esgoto doméstico coletado a jusante do filtro biológico com bagaço de cana-de-açúcar e EBS - esgoto doméstico coletado a jusante do filtro biológico com serragem de madeira). 
montante foi de $764 \mathrm{mg} \mathrm{L}^{-1}$ e, nos esgotos domésticos coletados a jusante dos biofiltros preenchidos com lixo compostado, bagaço de cana-de-açúcar e serragem de madeira, essas concentrações foram de 569, 496 e 478 $\mathrm{mg} \mathrm{L}^{-1}$, apresentando remoções de ST de 25, 35 e 37\%, respectivamente (Figura 3).

No aproveitamento agrícola do esgoto doméstico, concentrações excessivas de SS e ST podem prejudicar o desempenho do sistema de aplicação, por meio do entupimento de emissores, bem como pela obstrução dos poros do solo, o que resulta em redução da infiltração e condutividade hidráulica de efluente no solo. Nos esgotos domésticos coletados a montante dos biofiltros, preenchidos com lixo compostado, bagaço de cana-de-açúcar e serragem de madeira, sob as taxas de aplicação de 0,$5 ; 1,0 ;$ e $1,5 \mathrm{~m}^{3} \mathrm{~m}^{-2} \mathrm{~d}^{-1}$, as concentrações de SS oscilaram de 144 a $196 \mathrm{mg} \mathrm{L}^{-1}$; enquanto, nos esgotos domésticos coletados a jusante desses biofiltros, as concentrações de SS atingiram valores de 23 a $68 \mathrm{mg} \mathrm{L}^{-1}$. De acordo com classificação proposta por Nakayama et al. (2006), o risco de obstrução de gotejadores do esgoto doméstico passou de severo para menor, ou moderado, dependendo do tipo de biofiltro ou taxa de aplicação de esgoto doméstico. Em relação a ST, os valores obtidos a montante dos biofiltros preenchidos com lixo compostado, bagaço de cana-de-açúcar e serragem de madeira, sob as taxas de aplicação de 0,$5 ; 1,0 ;$ e $1,5 \mathrm{~m}^{3} \mathrm{~m}^{-2} \mathrm{~d}^{-1}$, as concentrações de $\mathrm{SS}$ variaram de 924 a $988 \mathrm{mg} \mathrm{L}^{-1}$; enquanto as concentrações de ST, no esgotos doméstico coletado a jusante dos biofiltros, oscilaram de 458 a $663 \mathrm{mg} \mathrm{L}^{-1}$; nessas condições, o risco de obstrução de gotejadores permaneceu como moderado (Nakayama et al., 2006).
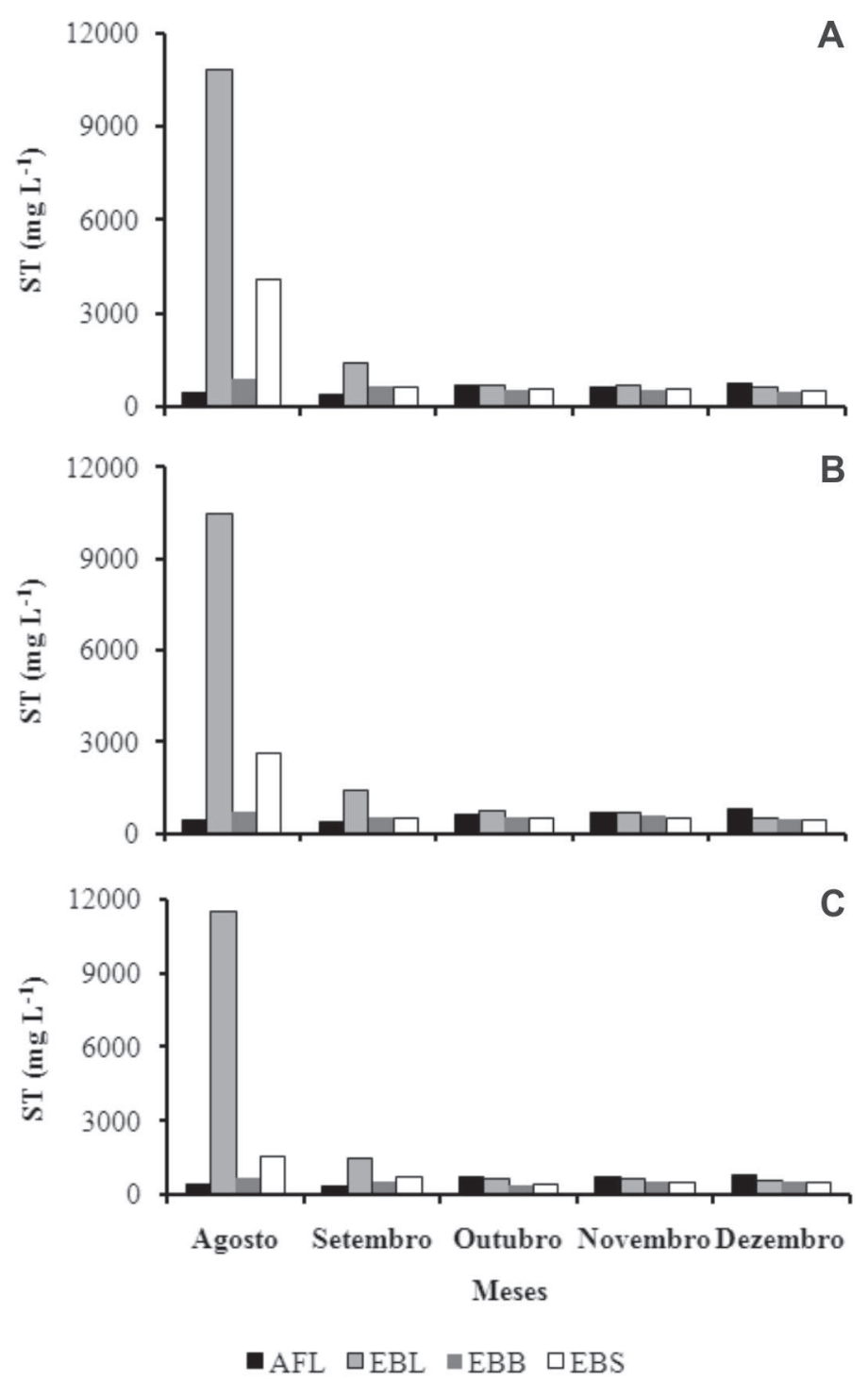

Figura 3. Concentrações dos sólidos totais (ST) das amostras de esgoto doméstico, coletadas a montante e a jusante dos biofiltros, submetidos às taxas de aplicação de 0,5 (a), 1,0 (b) e 1,5 (c) $\mathrm{m}^{3} \mathrm{~m}^{-2} \mathrm{~d}^{-1}$ (AFL - esgoto doméstico sem tratamento, EBL - esgoto doméstico coletado a jusante do filtro biológico com lixo compostado, EBB - esgoto doméstico coletado a jusante do filtro biológico com bagaço de cana-de-açúcar e EBS - esgoto doméstico coletado a jusante do filtro biológico com serragem de madeira). 
O experimento ocorreu de agosto a dezembro de 2009 , totalizando um período de operação de 153 dias. Não foram observados, durante o período experimental, problemas de entupimento dos meios filtrantes, tendo em vista que as minhocas atuavam na formação de caminhos preferenciais, que favoreceram a infiltração do esgoto doméstico. Em relação ao arraste de sólidos totais (ST) e sólidos suspensos (SS), foram notados comportamentos distintos. Nos biofiltros preenchidos com lixo compostado, houve liberação de ST nos primeiros 60 dias de operação, enquanto, para SS, esse comportamento não foi observado. Durante o período experimental foi verificada degradação mais acelerada do bagaço de cana-de-açúcar, em relação às do lixo compostado e da serragem de madeira, em função do rebaixamento desse resíduo no interior dos biofiltros.

Na Tabela 2, encontra-se o resumo da análise de variância dos valores de remoção de SS e ST dos biofiltros, no esquema de parcelas subsubdivididas. Verificou-se, na variável de remoção de SS, que a interação taxa de aplicação de esgoto doméstico (TA) x tipo de material filtrante (TF) x período de aplicação (PA) foi não significativa, a $5 \%$ de probabilidade. No entanto, para a variável remoção de ST a interação TA x TF x PA foi significativa, a $1 \%$ de probabilidade (Tabela 2). A utilização de biofiltros minimiza a obstrução de emissores, causada por sólidos suspensos, quando do aproveitamento agrícola de esgoto doméstico, por via do sistema de irrigação por gotejamento.

Para estudar o desempenho dos biofiltros, considerou-se significativa a interação TA x TF x PA para a variável de remoção de SS. Em vista dos resultados das análises de variância, procedeu-se ao desdobramento da interação TA x TF x PA para as variáveis de remoção de SS e ST.
Estão apresentados, na Tabela 3, os valores médios de remoção SS (\%) para o fator tipo de material orgânico, dentro de cada nível de período de aplicação e cada nível de taxa de aplicação. Constata-se, nesse quadro, que não houve efeito das taxas de aplicação de esgoto doméstico sobre a remoção de SS, para cada tipo de material orgânico, após 153 dias de operação. Verifica-se, nos trabalhos apresentados por Batista et al. (2011) e Batista et al. (2012), desempenho semelhante desses biolfiltros, no que se refere à remoção de condutividade elétrica, DQO e DBO de esgoto doméstico primário (Tabela 3).

Comparando-se as médias da variável de remoção de $\mathrm{SS}$, seguidas de pelo menos uma mesma letra maiúscula, nas colunas da Tabela 3, verificou-se que: a remoção de SS nos biofiltros com serragem de madeira submetidos à taxa de aplicação de esgoto doméstico de $0,5 \mathrm{~m}^{3} \mathrm{~m}^{-2} \mathrm{~d}^{-1}$, diferiu das demais taxas, no mês de agosto de 2009; os biofiltros com lixo compostado, submetidos à taxa de aplicação de esgoto doméstico de $1,0 \mathrm{~m}^{3} \mathrm{~m}^{-2} \mathrm{~d}^{-1}$, apresentaram remoção de SS que diferiu das obtidas nas taxas de aplicação de esgoto doméstico de 0,5 e $1,5 \mathrm{~m}^{3} \mathrm{~m}^{-2} \mathrm{~d}^{-1}$, no mês de novembro de 2009; e a remoção de SS nos biofiltros dotados de serragem de madeira, submetidos à taxa de aplicação de esgoto doméstico de $1,0 \mathrm{~m}^{3} \mathrm{~m}^{-2} \mathrm{~d}^{-1}$, diferiu das demais taxas de aplicação, no mês de dezembro de 2009.

Analisando-se as médias da variável de remoção de SS, seguidas de pelo menos uma mesma letra minúscula, nas linhas da Tabela 3, observou-se que: nos meses de agosto e setembro de 2009, a remoção de SS, nos biofiltros dotados de lixo compostado submetidos às taxas de aplicação de esgoto doméstico de 0,5, 1,0 e 1,5 $\mathrm{m}^{3} \mathrm{~m}^{-2} \mathrm{~d}^{-1}$, diferiram nos biofiltros com bagaço de cana-de-açúcar. Esse fato atribuise ao arraste de partículas presentes no lixo compostado, durante o período de aplicação do esgoto doméstico, em

Tabela 2. Resumo das análises de variância dos dados obtidos para as variáveis SS e ST presentes em amostras de esgoto doméstico submetidas a diferentes tratamentos de filtragem, com diferentes taxas de aplicação e épocas de avaliação, no esquema de parcelas subsubdivididas

\begin{tabular}{lccc}
\hline \multirow{2}{*}{ Fonte de variação } & Grau de liberdade & \multicolumn{2}{c}{ Quadrado médio } \\
\cline { 3 - 4 } & & S S & S T \\
\hline TA & 2 & $2508 * *$ & $1,40 \times 10^{4 * *}$ \\
Resíduo (a) & 6 & 203 & 1146 \\
TF & 2 & $1,18 \times 10^{4 * *}$ & $3,50 \times 10^{6 * *}$ \\
TA x TF & 4 & $892^{* *}$ & $2,64 \times 10^{4 * *}$ \\
Resíduo (b) & 12 & 178 & 3245 \\
PA & 4 & $1844 * *$ & $5,38 \times 10^{6 * *}$ \\
TA x PA & 8 & $518^{*}$ & $1,26 \times 10^{4 * *}$ \\
TF x PA & 8 & $977^{* *}$ & $2,60 \times 10^{6 * *}$ \\
TA x TF x PA & 16 & $294^{\mathrm{ns}}$ & $2,56 \times 10^{4 * *}$ \\
Resíduo (c) & 72 & 227 & 4011 \\
\hline
\end{tabular}

**, $*$ e ns $\mathrm{F}$ significativos a 1 e $5 \%$ de probabilidade e não significativo a $5 \%$ de probabilidade, respectivamente. TA= taxa de aplicação; $\mathrm{TF}=$ tipo de material filtrante; $\mathrm{PA}=$ período de aplicação. 
função de pouca formação de biofilme entre as partículas orgânicas do meio filtrante. Com o passar do tempo, houve aumento no nível populacional dos micro-organismos nos meios filtrantes, acarretando a formação de biofilme, com capacidade de retenção de material particulado de forma mais eficiente, bem como sua degradação.

Constam, na Tabela 4, os valores médios de remoção de ST para o fator tipo de material orgânico, dentro de cada nível de período de aplicação e cada nível de taxa de aplicação. Observa-se, nesse quadro, que não houve efeito das taxas de aplicação de esgoto doméstico sobre a remoção de ST, para cada tipo de material orgânico, após 153 dias de operação (Tabela 4).

Analisando-se as médias da variável de remoção de ST, seguidas de pelo menos uma mesma letra maiúscula nas colunas da Tabela 4, constatou-se que: a remoção de ST nos biofiltros com lixo compostado, submetidos à taxa de aplicação de esgoto doméstico de $1,5 \mathrm{~m}^{3} \mathrm{~m}^{-2} \mathrm{~d}^{-1}$,

Tabela 3. Remoção de SS (\%) por diferentes tipos de material orgânico filtrante em diferentes épocas de avaliação e com diferentes taxas de aplicação de esgoto doméstico

\begin{tabular}{|c|c|c|c|c|}
\hline \multirow{2}{*}{ Tempo de aplicação } & \multirow{2}{*}{$\begin{array}{l}\text { Tipos de materiais } \\
\text { orgânicos }\end{array}$} & \multicolumn{3}{|c|}{ Taxa de aplicação $\left(\mathrm{m}^{3} \mathrm{~m}^{-2} \mathrm{~d}^{-1}\right)$} \\
\hline & & 0,5 & 1,0 & 1,5 \\
\hline \multirow{3}{*}{ Agosto } & Lixo & $12 \mathrm{Ab}$ & $21 \mathrm{Ab}$ & $38 \mathrm{Ab}$ \\
\hline & Bagaço & 76Aa & $76 \mathrm{Aa}$ & $82 \mathrm{Aa}$ \\
\hline & Serragem & $13 \mathrm{Bb}$ & $73 \mathrm{Aa}$ & 66Aab \\
\hline \multirow{3}{*}{ Setembro } & Lixo & $36 \mathrm{Ab}$ & $37 \mathrm{Ab}$ & $12 \mathrm{Ab}$ \\
\hline & Bagaço & 80Aa & $82 \mathrm{Aa}$ & 79Aa \\
\hline & Serragem & $62 \mathrm{Aab}$ & 74Aa & 70Aa \\
\hline \multirow{3}{*}{ Outubro } & Lixo & $32 \mathrm{Aa}$ & $51 \mathrm{Aa}$ & $55 \mathrm{Aa}$ \\
\hline & Bagaço & $50 \mathrm{Aa}$ & $74 \mathrm{Aa}$ & $78 \mathrm{Aa}$ \\
\hline & Serragem & $44 \mathrm{Aa}$ & $66 \mathrm{Aa}$ & $67 \mathrm{Aa}$ \\
\hline \multirow{3}{*}{ Novembro } & Lixo & $59 \mathrm{Aba}$ & $39 \mathrm{Bb}$ & $73 \mathrm{Aa}$ \\
\hline & Bagaço & $75 \mathrm{Aa}$ & $73 \mathrm{Aa}$ & $66 \mathrm{Aa}$ \\
\hline & Serragem & $54 \mathrm{Aa}$ & $82 \mathrm{Aa}$ & $78 \mathrm{Aa}$ \\
\hline \multirow{3}{*}{ Dezembro } & Lixo & $60 \mathrm{Aa}$ & $72 \mathrm{Aa}$ & $58 \mathrm{Aa}$ \\
\hline & Bagaço & $78 \mathrm{Aa}$ & $78 \mathrm{Aa}$ & 86Aa \\
\hline & Serragem & $56 \mathrm{Ba}$ & 86Aa & 71Aba \\
\hline
\end{tabular}

* Médias seguidas de pelo menos uma mesma letra maiúscula, nas colunas, para cada período de aplicação e minúscula, nas linhas, para cada taxa de aplicação não diferem entre si, a 5\% de probabilidade, pelo teste de Tukey.

Tabela 4. Remoção de ST (\%) por diferentes tipos de material orgânico filtrante em diferentes épocas de avaliação e com diferentes taxas de aplicação de esgoto doméstico

\begin{tabular}{|c|c|c|c|c|}
\hline \multirow{2}{*}{ Tempo de aplicação } & \multirow{2}{*}{$\begin{array}{l}\text { Tipos de materiais } \\
\text { orgânicos }\end{array}$} & \multicolumn{3}{|c|}{ Taxa de aplicação $\left(\mathbf{m}^{3} \mathbf{m}^{-2} \mathrm{~d}^{-1}\right)$} \\
\hline & & 0,5 & 1,0 & 1,5 \\
\hline \multirow{3}{*}{ Agosto } & Lixo & $-2357 \mathrm{Ac}$ & $-2285 \mathrm{Ac}$ & $-2575 \mathrm{Bc}$ \\
\hline & Bagaço & $-106 \mathrm{Aa}$ & $-59 \mathrm{Aa}$ & $-60 \mathrm{Aa}$ \\
\hline & Serragem & $-831 \mathrm{Ab}$ & $-498 \mathrm{Bb}$ & $-262 \mathrm{Cb}$ \\
\hline \multirow{3}{*}{ Setembro } & Lixo & $-243 \mathrm{Ab}$ & $-265 \mathrm{Ab}$ & $-296 \mathrm{Ab}$ \\
\hline & Bagaço & $-58 \mathrm{Aa}$ & $-41 \mathrm{Aa}$ & $-36 \mathrm{Aa}$ \\
\hline & Serragem & $-60 \mathrm{Aa}$ & $-36 \mathrm{Aa}$ & $-88 \mathrm{Aa}$ \\
\hline \multirow{3}{*}{ Outubro } & Lixo & $-3 \mathrm{Aa}$ & $-25 \mathrm{Aa}$ & $8 \mathrm{Aa}$ \\
\hline & Bagaço & $26 \mathrm{Aa}$ & $16 \mathrm{Aa}$ & $41 \mathrm{Aa}$ \\
\hline & Serragem & 19Aa & 19Aa & $35 \mathrm{Aa}$ \\
\hline \multirow{3}{*}{ Novembro } & Lixo & $-8 \mathrm{Aa}$ & $3 \mathrm{Aa}$ & $12 \mathrm{Aa}$ \\
\hline & Bagaço & $18 \mathrm{Aa}$ & $15 \mathrm{Aa}$ & $24 \mathrm{Aa}$ \\
\hline & Serragem & $12 \mathrm{Aa}$ & $26 \mathrm{Aa}$ & $26 \mathrm{Aa}$ \\
\hline \multirow{3}{*}{ Dezembro } & Lixo & $22 \mathrm{Aa}$ & $34 \mathrm{Aa}$ & $25 \mathrm{Aa}$ \\
\hline & Bagaço & 39Aa & $40 \mathrm{Aa}$ & $35 \mathrm{Aa}$ \\
\hline & Serragem & $31 \mathrm{Aa}$ & $42 \mathrm{Aa}$ & $37 \mathrm{Aa}$ \\
\hline
\end{tabular}

* Médias seguidas de pelo menos uma mesma letra maiúscula, nas colunas, para cada período de aplicação e minúscula, nas linhas, para cada taxa de aplicação não diferem entre si, a 5\% de probabilidade, pelo teste de Tukey.

Rev. Ceres, Viçosa, v. 60, n.1, p. 007-015, jan/fev, 2013 
diferiram das médias das demais taxas de aplicação, enquanto a remoção de ST nos biofiltros com serragem de madeira, submetidos às taxas de aplicação de esgoto doméstico de $0,5,1,0$ e $1,5 \mathrm{~m}^{3} \mathrm{~m}^{-2} \mathrm{~d}^{-1}$, diferem entre si, no mês de agosto de 2009 .

Comparando-se as médias da variável de remoção de ST, seguidas de pelo menos uma mesma letra minúscula nas linhas da Tabela 4, constatou-se que: no mês de agosto de 2009, a remoção de ST nos biofiltros com lixo compostado, bagaço de cana-de-açúcar e serragem de madeira, submetidos às taxas de aplicação de esgoto doméstico de $0,5,1,0$ e $1,5 \mathrm{~m}^{3} \mathrm{~m}^{-2} \mathrm{~d}^{-1}$, diferem entre si; e, no mês de setembro de 2009, os biofiltros com lixo compostado, submetidos às taxas de aplicação de esgoto doméstico de $0,5,1,0$ e $1,5 \mathrm{~m}^{3} \mathrm{~m}^{-2} \mathrm{~d}^{-1}$, apresentaram taxa de remoção de ST que diferiu da obtida nos biofiltros com os demais tipos de materiais orgânicos.

O uso de filtro biológico para o tratamento de esgoto doméstico consiste em uma tecnologia de baixo custo, de fácil operação e elevada eficiência de remoção de sólidos suspensos.

\section{CONCLUSÃO}

Após 153 dias de operação, os biofiltros proporcionaram remoções de até $82 \%$ dos sólidos suspensos e $46 \%$ dos sólidos totais do esgoto doméstico.

A serragem de madeira foi o material orgânico filtrante com melhor desempenho no tratamento de esgoto doméstico.

As taxas de aplicação de $0,5,1,0$ e $1,5 \mathrm{~m}^{3} \mathrm{~m}^{-2} \mathrm{~d}^{-1} \mathrm{de}$ esgoto não apresentaram diferenças, quanto à remoção de sólidos suspensos e totais.

\section{REFERÊNCIAS}

Batista RO, Barreto HBF, Alves SMC, Santos WO \& Freire FGC (2012) Remoção de nitrato e condutividade elétrica em biofiltros operando com esgoto doméstico primário. Global Science and Technology, 5:59-69.

Batista RO, Sartori MA, Soares AA, Moura FN \& Costa Paiva MR (2011) Potencial da remoção de poluentes bioquímicos em biofiltros operando com esgoto doméstico. Revista Ambiente \& Água - An Interdisciplinary Journal of Applied Science, 6:152-164.

Batista RO, Souza JAR \& Ferreira DC (2010) Influência da aplicação de esgoto doméstico tratado no desempenho de um sistema de irrigação. Revista Ceres, 57:18-22.

Fernández-Gómez MJ, Nogales R, Insam H, Romero E \& Goberna M (2012) Use of DGGE and COMPOCHIP for investigating bacterial communities of various vermicomposts produced from different wastes under dissimilar conditions. Science of the Total Environment, 414:664-671.

Fu Y, Shao L, Liu H, Tong L \& Liu H (2011) Ethylene removal evaluation and bacterial community analysis of vermicompost as biofilter material. Journal of Hazardous Materials 192:658-666.
Intituto Brasileiro de Geografia e Estatística - IBGE (2010) Pesquisa nacional de saneamento básico 2008. Rio de Janeiro, MPOG/MC. 219p.

Jeong E, Hirai M \& Shoda M (2008) Removal of o-xylene using biofilter inoculated with Rhodococcus sp. BTO62. Journal of Hazardous Materials, 152:140-147.

Jun Y \& Wenfeng X (2009) Ammonia biofiltration and community analysis of ammonia-oxidizing bacteria in biofilters. Bioresource Technology, 100:3869-3876.

Kim D \& Sorial GA (2007) Role of biological activity and biomass distribution in air biofilter performance. Chemosphere, 66:17581764.

Laws JEA (2003) Evaluación ambiental del sistema Tohá em la remoción de Salmonella en aguas servidas domésticas. Magister en Gestión y Planificación Ambiental. Universidad de Chile, Santiago. 92p.

Moon KE, Lee SY, Lee SH, Ryu HW \& Cho KS (2010) Earthworm cast as a promising filter bed material and its methanotrophic contribution to methane removal. Journal of Hazardous Materials, 176:131-138.

Nakayama FS, Boman BJ \& Pitts D (2006) Maintenance. In: Lamm FR, Ayars JE \& Nakayama FS (Eds.) Microirrigation for crop production: Design, Operation, and Management. Amsterdam, Elsevier. p.389-430.

Ribeiro Júnior JI \& Melo ALP (2008) Guia prático para utilização do SAEG. Viçosa, Editora UFV. 288p.

Sanches-Roman R, Soares AA, Matos AT, Sediyama GC, Souza O \& Mounteer HA (2007) Domestic wastewater disinfection using solar radiation for agricultural reuse. Transactions of the ASABE, 50:65-71

Von Sperling M (2011) Princípios do tratamento biológico de águas residuárias: Introdução à qualidade das águas e ao tratamento de esgotos. Belo Horizonte, UFMG. 452p.

Wang L, Zheng Z, Luo X \& Zhang J (2011) Performance and mechanisms of a microbial-earthworm ecofilter for removing organic matter and nitrogen from synthetic domestic wastewater. Journal of Hazardous Materials, 195:245-253.

Xing M, Yang J, Wang Y, Liu J \& Yu F (2011) A comparative study of synchronous treatment of sewage and sludge by two vermifiltrations using an epigeic earthworm Eisenia fetida. Journal of Hazardous Materials, 185:881-888.

Zhao L, Wang Y, Yang J, Xing M, Li X, Yi D \& Deng D (2010) Earthworm-microorganism interactions: A strategy to stabilize domestic wastewater sludge. Water Research, 44:2572-2582. 